\title{
O trabalho de assistentes sociais na defesa dos direitos da população em situação em/na rua em debate
}

\section{The work of social workers in the defense of the rights of the population in/on the street under debate}

\author{
Meiry Farias Corrente ${ }^{1}$, Ângela Maria Pereira da Silva ${ }^{1}$, Gehysa Guimarães Alves ${ }^{1}$, Tainara da \\ Rosa $^{1}$
}

\section{RESUMO}

Este artigo apresentará uma reflexão sobre a experiência teórico-prática advinda do Estágio em Serviço Social II, realizado no âmbito da Política de Assistência Social e da Política de Defesa dos Direitos das Pessoas em Situação de/na Rua. Foram analisados os resultados do Projeto de intervenção voltado aos usuários atendidos no Centro Pop de Novo Hamburgo (NH), no Rio Grande do Sul (RS), durante o período de março a julho de 2021. Este projeto de intervenção é uma via para ampliar o acesso à rede de proteção social, conforme preconizado em ambas as políticas. O espaço do estágio em Serviço Social norteia-se pelas portarias que falam sobre as competências e atribuições do Centro Pop, mediante a precarização das relações e condições de trabalho da equipe, seus rebatimentos na Política de Assistência Social e, consequentemente, na qualidade dos serviços sociais. Por isso, esta discussão é relevante e serve como subsídio para repensar o cotidiano de trabalho, em especial o agravamento da questão social. Tal artigo será discutido a partir do método do materialismo dialético. No que se refere aos resultados e discussões, foi evidenciada a reafirmação dos direitos sociais dessa parcela da população que vive a (des)proteção, a invisibilidade e o adoecimento, em especial, na pandemia do Novo Coronavírus - Covid-19.

Palavras-chave: Pessoas em situação de rua; (Des)proteção social; Centro Pop.

\begin{abstract}
This article will present a reflection on the theoretical-practical experience arising from the Internship in Social Work II, carried out within the scope of the Social Assistance Policy and the Policy for the Defense of the Rights of People in/on the Street. The results of the intervention project aimed at users served at Centro Pop de Novo Hamburgo (NH), in Rio Grande do Sul (RS), during the period from March to July 2021, were analyzed. This intervention project is a way to expand access to the social protection network, as recommended in both policies. The space of the internship in Social Work is guided by the ordinances that talk about the competencies and attributions of Centro Pop, through the precariousness of the relationships and working conditions of the team, its repercussions in the Social Assistance Policy and, consequently, in the quality of services. social. Therefore, this discussion is relevant and serves as a subsidy to rethink the daily work, especially the aggravation of the social issue. This article will be discussed from the method of dialectical materialism. With regard to the results and discussions, the reaffirmation of the social rights of this part of the population living with (un)protection, invisibility and illness was evidenced, especially in the New Coronavirus - Covid-19 pandemic.
\end{abstract}

\footnotetext{
${ }^{1}$ Instituição de afiliação: Universidade Luterana do Brasil - Ulbra

E-mail: tainaradarosa7@ gmail.com
} 
Keywords: Homeless people; (Dis) protection social; Pop Center.

\section{INTRODUÇÃO}

O estágio de campo do curso de Graduação em Serviço Social foi desenvolvido no período de março a julho de 2021, no Centro Pop de Novo Hamburgo/RS. A população desta cidade é composta por 247.303 mil pessoas, além daquelas oriundas de outros municípios (IBGE, 2020).

Entre as demandas do estágio, vale ressaltar a estratégia de sobrevivência da população em situação de/na rua, frente aos mínimos sociais, como reitera Costa (2005). Esta questão será aprofundada no subitem 1, a fim de descrever as expressões da questão social manifestadas nas demandas da população usuária do Centro Pop de Novo Hamburgo.

Também é necessária a compreensão da linha do tempo da política de assistência social no Brasil, especialmente no âmbito do atendimento à população em situação de/na rua para subsidiar os relatos destacados pela experiência do estágio em Serviço Social II. Neste artigo, tal discussão constará no subitem 2, em que aborda-se a inter-relação entre a Política Nacional de Assistência Social e a Política Nacional da Pessoa em Situação de Rua.

Ressalta-se que a inserção no campo de estágio ocorreu em meio à pandemia, em que todos/as, por medida de segurança, estiveram em distanciamento social, decretado pela OMS (Organização Mundial da Saúde) para prevenir o contágio do Novo Coronavírus (Covid-19). Dito isso, a intervenção realizada pela acadêmica visou à ampliação de estratégias de sobrevivência, segurança alimentar, saúde e vagas em serviço de acolhimento institucional, mediante a inexistência de política habitacional, já que esta foi encerrada em 2015. Estas situações serão debatidas com profundidade no item 3 deste artigo, intitulado "o Processo de Trabalho de assistentes sociais no Centro Pop: desafios e possibilidades na pandemia".

Em maio de 2020, o Jornal de Novo Hamburgo publicou uma notícia afirmando que houve um aumento no número de pessoas que viviam em situação de/na rua nos meses que antecederam à notícia, chegando a mais 30\% (MELLO, 2021). Ao encontro disso, o Instituto de Pesquisa Econômica Aplicada (IPEA, 2020) divulgou um aumento 
de $140 \%$ no que tange as pessoas em situação de/na rua no Brasil, no período de 2012 a 2020, quase totalizando o número de 222 mil pessoas nessa conjuntura. Cabe então aos estudiosos e interventores sociais atentarem-se para o agravamento da questão social, ou seja, a piora no âmbito das violações de direitos desse determinado segmento. Neste sentido, estudar essa temática possibilita a compreensão de novas estratégias e também de outros conhecimentos que subsidiarão os gestores da política da assistência social de Novo Hamburgo sobre programas e projetos sociais a essa população.

\section{METODOLOGIA}

Conforme Gil (2008), a pesquisa observacional é um método bastante eficaz na pesquisa social, pois é através da observação que se tem dados mais precisos de determinada situação, a fim de produzir informações sobre um tema em especifico. Assim, optou-se por escolher este delineamento para este estudo. Para Lewgoy e Silveira (2007), a observação é fundamental no registro de assistentes sociais, uma vez que é desta forma que o profissional consegue captar informações que estão sendo narradas ou expressadas corporalmente.

Neste artigo, utiliza-se uma abordagem qualitativa que, conforme Minayo (2002), configura-se como uma pesquisa das informações que não podem ser medidas, trazendo a realidade de vida, as relações sociais e o cotidiano dos usuários. Corroborando com isto, alguns excertos de relatos de experiência registrados no diário de campo serão mencionados nos resultados e discussão.

Para a realização desta pesquisa, parte-se das ações desenvolvidas no projeto de intervenção com sujeitos, assim qualificados: duas do sexo feminino e cinco do sexo masculino, na faixa etária entre 20 a 50 anos de idade e baixa escolarização, sendo que boa parte desses usuários são beneficiários do Programa Federal Bolsa Família²

A coleta de dados foi realizada por meio de entrevistas com sete usuários, no período de março a julho de 2021, e também por meio de observação participante, sendo esta a forma mais clara de mostrar a realidade do pesquisado (LEWGOY; SILVEIRA, 2007). Ademais, há os registros no diário de campo que compõem parte dos dados que serão contextualizados, a fim de demonstrar os pormenores desta inter-relação com os sujeitos participantes (LIMA; MIOTO; DAL PRÁ, 2007).

2 O Programa Federal Bolsa Família é uma política pública contribui para o combate à pobreza e à desigualdade no Brasil. 
A análise de conteúdo temático ocorreu com base em Bardin (2016), em decorrência da sua funcionalidade no manuseio dos dados referentes às entrevistas e às narrativas dos usuários em situação de/na rua, atendidos no projeto de intervenção. Neste método de análise é realizada a pré-análise, a exploração do material e o tratamento dos resultados, tais como são descritos pela autora.

Para este estudo, buscou-se respaldo no materialismo dialético crítico para fundamentar teoricamente o processo de trabalho de assistentes sociais no Centro Pop de Novo Hamburgo, com o intuito de entender as diretrizes para atendimento à população em situação de/na rua, na intencionalidade de melhoria nas intervenções.

\title{
AS EXPRESSÕES DA QUESTÃO SOCIAL MANIFESTADAS NAS DEMANDAS DA POPULAÇÃO USUÁRIA DO CENTRO POP DE NOVO HAMBURGO
}

No espaço sócio-ocupacional Centro Pop de Novo Hamburgo, é realizada a abordagem à população adulta em situação de/na rua e, de modo geral, o serviço é acessado por pessoas desassistidas de seus direitos sociais, o que demarca uma desigualdade na sociedade brasileira. Conforme o IPEA (2020), parte deste segmento social vivencia a miserabilidade ${ }^{3}$ das ruas nos municípios com mais de 100 mil habitantes, ou seja, subentende-se que as grandes metrópoles são as mais habitáveis devido às estratégias de sobrevivência 4 .

O aumento dessa população tem relação direta com o agravamento sociocultural e econômico incidido pela exacerbação do desemprego estrutural, da ausência de programas habitacionais, da crise do capital, da pandemia de Covid-19, entre outros fatores. Segundo Iamamoto (1999), a questão social pode ser definida como:

\begin{abstract}
O conjunto das expressões das desigualdades da sociedade capitalista madura, que têm uma raiz comum: a produção social é cada vez mais coletiva, o trabalho torna-se mais amplamente social, enquanto a apropriação dos seus frutos se mantém privada, monopolizada por uma parte da sociedade (IAMAMOTO, 1999, p. 27).
\end{abstract}

Assim, pode-se afirmar que a questão social é expressa através das relações entre o capital versus trabalho. Esta contradição entre quem detém o poder e a força de trabalho

\footnotetext{
${ }^{3}$ Conforme a Lei Orgânica da Assistência Social (Lei no 8.742 de 1993), artigo 20, $\S 3^{\circ}$, as famílias que possuem renda per capita menor que $1 / 4$ do salário mínimo vigente do nosso país não conseguem prover seu sustento e, por isso, estão aptas a receber o Benefício de Prestação Continuada.

${ }^{4}$ Como estratégias de sobrevivência temos o auxílio emergencial, benefício financeiro concedido pelo Governo Federal com objetivo de fornecer proteção emergencial no período de enfrentamento à crise causada pela pandemia do Coronavírus - Covid-19.
} 
amplia as desigualdades econômica, cultural, política e social (IAMAMOTO, 2001), o que se soma, ainda, ao preconceito e a discriminação, pois geralmente os usuários são invisibilizados no sistema de proteção social brasileiro e, também, pela própria sociedade.

Para Crochik (2006), o preconceito é uma das formas de desprezo e intolerância, ressaltando o que há de "errado" no outro. Neste sentido, os usuários atendidos no projeto de intervenção estavam suscetíveis ao preconceito, pois se encontravam em disputa desigual pelo acesso ao trabalho, à renda, à habitação, à educação, à assistência social, à saúde, entre outros. Mostra-se, assim, que a lógica do mercado sobrepõe-se a dos Direitos Humanos, e este segmento social se encontra em desvantagens em relação a outros cidadãos/as, já que geralmente não detém documentos pessoais, moradia e escolarização, isto é, estão excluídos de todos os benefícios do Estado.

Deste modo, é possível compreender que essa população é a representação da exclusão social e, conforme Demo (1998) é produto das relações capitalistas, que têm como processo a privação de estarem no grupo de excluídos, o que limita o acesso ao lazer, à saúde, à educação e ao trabalho, e recrudesce o empobrecimento, tornando a classe excluída como os protagonistas principais dos "despossuídos e destituídos" (SPOSATI; FALCÃO; FLEURY, 2015).

Na vida cotidiana, esses usuários experenciam situações de "mendicância" ou de trabalhos esporádicos (jardinagem, cata e reciclagem, venda de produtos em semáforos, flanelinha, etc.), o que os faz adentrar na zona de informalidade e do trabalho desprotegido. Ressalta-se, ainda, que estes usuários sequer têm condições de disputar vagas de trabalho, pois muitos se encontram com restrição cadastral, sem endereço fixo, sem condições de custear a procura de um emprego, sem condições de higiene, além de não disporem da documentação e da capacitação exigida, encontrando-se em desvantagem, pois não atingem o perfil profissiográfico (HERMANSON, 2019).

O desemprego tem subido cada vez mais no Brasil, conforme apontam o IBGE (2021), Pochmann (2015-2018), sendo que a maior taxa de desemprego dos últimos anos, antes da pandemia, ocorreu em 2004, com $13,1 \%$, e a menor taxa ocorreu em 2014, com 4,3\%. Já durante a pandemia, no primeiro semestre de 2021, a taxa de desemprego chegou a $14,7 \%$, ampliando a dificuldade na conquista de empregos.

Esta situação tem se agravado à medida que o Estado se exime de reagir. Ao encontro disso, em 2016, o site do Instituto Humanitas, da Unisinos já havia alertado para o aumento das pessoas que estavam vivendo em situação de/na rua. A partir de dados 
disponibilizados pela Fiocruz (GAMEIRO, 2021), nota-se que este quadro tem acelerado durante a pandemia de Covid-19, pois o quantitativo de pessoas, que já girava em torno dos 221 mil, ampliou-se consideravelmente após um ano e oito meses do início da doença. Isso mostra o quanto o Brasil é carente de políticas públicas, já que frases como "fique em casa" ou "use máscara" não são efetivas, de fato, para esse segmento.

Neste contexto, essa população sofre com os rebatimentos da crise do capital, com a precarização das políticas públicas e com as restrições no acesso aos equipamentos sociais em meio à pandemia, visto que muitos órgãos públicos iniciaram agendamentos e/ou atendimentos online, dificultando ainda mais o acesso desses usuários ao sistema de proteção social e a programas sociais, pois parte dessa população não tem acesso a celulares, não possuem ou perderam seus dados, e/ou não se lembram da data de nascimento e cidade de origem (SANTOS; FACHIN, 2020).

A realidade social exposta revela que esta parte da população fica à mercê dos mínimos sociais e não das necessidades básicas. Apesar dos termos serem parecidos, o conceito de "mínimos sociais" está ligado diretamente à provisão de alimento, moradia, higienização e saúde, entre outros, enquanto o conceito de necessidades básicas requer um trabalho em cima de atendimentos preparatórios, provisionando o investimento de tempo e recurso para proporcionar aos usuários uma chance de inclusão social (PEREIRA, 2011).

A (des) proteção que sofre essa população também envolve a burocratização no acesso aos programas, projetos e políticas, a precarização de atendimento, a ausência de recursos e a capacidade insuficiente nos Centros Pop, como nas redes, tanto o SUS (Sistema Único de Saúde), quanto o SUAS (Sistema Único de Assistência Social). Ao encontro desta realidade, Reinholz (2019) reitera que o enfraquecimento da rede de proteção acaba fragilizando os vínculos da equipe, das famílias, com/entre os usuários.

O enfrentamento das expressões da questão social é o objeto de trabalho do assistente social, e no cotidiano do Centro Pop busca-se a informatização, fortalecimento da identidade, autonomia e cidadania dos usuários. A abordagem desse processo de trabalho será contextualizada na inter-relação entre a Política Nacional de Assistência Social e a Política Nacional da Pessoa em Situação de Rua.

A INTER-RELAÇÃo ENTRE A POLÍtiCA NACIONAL DE ASSISTÊNCIA SOCIAL E A POLÍTICA NACIONAL DA PESSOA EM SITUAÇÃO DE RUA 
A Constituição Federal de 1988 (BRASIL, 1988) foi um marco no âmbito da política de assistência social no Brasil, pois foi instituída como um dever do Estado e um direito a quem dela necessitar. Destacam-se, na referida legislação, os artigos $203^{5}$ e $204^{6}$, devido à relação com a garantia dos mínimos sociais ${ }^{7}$ aos cidadãos, uma vez que a inclusão destes artigos no texto constitucional abriu precedentes para novos parâmetros no campo da política de assistência social no país através da reorganização do modelo do sistema, da gestão e das ações ofertadas à população usuária. Já a Lei Orgânica da Assistência Social de 1993 (LOAS) foi construída e instituída para que se materializassem os artigos do texto constitucional na vida da população (BRASIL, 1988; ALCHORNE, 2013).

A assistência social ampliou o acesso de usuários aos serviços socioassistenciais por meio da criação de programas sociais, além de benefícios eventuais, geralmente demandados pela equipe do Centro de Referência de Assistência Social (CRAS). Esta é articulada na rede de proteção básica, com atendimento voltado à população em situação de vulnerabilidade, visando a proteção social e a centralidade sociofamiliar, devendo prezar pela qualidade dos serviços e na ampliação de acesso aos direitos sociais a fim de incidir nas condições de vida e na emancipação dos cidadãos (BRASIL, 1993).

No entanto, notaram-se alguns desafios na materialização do que consta na LOAS, corroborando ao campo de estágio à medida que nem todos os direitos socioassistenciais

\footnotetext{
5 Art. 203: A assistência social será prestada a quem dela necessitar, independentemente de contribuição à seguridade social, com objetivos: I) a proteção à família, à maternidade, à infância, à adolescência e à velhice; II) o amparo às crianças e adolescentes carentes; III) a promoção da integração ao mercado de trabalho; IV) a habilitação e reabilitação das pessoas portadoras de deficiência e a promoção de sua integração à vida comunitária; V) a garantia de um salário mínimo de benefício mensal à pessoa portadora de deficiência e ao idoso que comprovem não possuir meios de prover à própria manutenção ou de tê-la provida por sua família, conforme dispuser a lei.
}

6 Art.204: As ações governamentais na área da assistência social serão realizadas com recursos do orçamento da seguridade social, previstos no art. 195, além de outras fontes, e organizadas com base nas seguintes diretrizes: I) descentralização político-administrativa, cabendo a coordenação e as normas gerais à esfera federal e a coordenação e a execução dos respectivos programas às esferas estadual e municipal, bem como a entidades beneficentes e de assistência social; II) participação da população, por meio de organizações representativas, na formulação das políticas e no controle das ações em todos os níveis. Parágrafo único. É facultado aos Estados e ao Distrito Federal vincular a programa de apoio à inclusão e promoção social até cinco décimos por cento de sua receita tributária líquida, vedada a aplicação desses recursos no pagamento de: (Incluído pela Emenda Constitucional no 42, de 19.12.2003): I) despesas com pessoal e encargos sociais; (Incluído pela Emenda Constitucional $\mathrm{n}^{\circ} 42$, de 19.12.2003), II) serviço da dívida; (Incluído pela Emenda Constitucional n $n^{\circ} 42$, de 19.12.2003), III) qualquer outra despesa corrente não vinculada diretamente aos investimentos ou ações apoiados. (Incluído pela Emenda Constitucional $\mathrm{n}^{\circ}$ 42, de 19.12.2003)

7 Para Sposati (1998), "propor mínimos sociais é estabelecer um patamar de cobertura de riscos e de garantias que uma sociedade quer garantir a todos os seus cidadãos [...] Trata-se de definir um padrão societário de civilidade". 
são facilmente acessados pelos usuários no Centro Pop, pois há critérios de inclusão, como a apresentação de documentos civis, de comprovante de endereço, acesso aos recursos tecnológicos para cadastramento prévio, entre outros. Deste modo, essas situações são excludentes para uma população historicamente desassistida e, por vezes, ainda invisibilizadas na sua representatividade política.

Em termos cronológicos, no âmbito da Política de Assistência Social, destacamse: a primeira Norma Operacional Básica da Assistência Social, datada de 1997 (NOB 1), voltada à transparência no uso dos recursos financeiros repassados pelo Fundo Nacional de Assistência Social e participação social nos conselhos de direito com enfoque total na construção do Sistema de Proteção Social; a segunda Norma Operacional Básica (NOB 2), estabelecida em 1998, que voltou-se para a descentralização político-administrativa da política de assistente social; e, por fim, a Norma Operacional Básica de 2005 (NOB/SUAS), que ampliou a reorganização e gestão em relação à transferência de recursos financeiros. Ademais, na IV Conferência Nacional de Assistência Social, ocorrida em 2007, foram pactuadas as responsabilidades de cada esfera de governo com relação à Proteção Social (ALCHORNE, 2013).

Além das normas, ressalta-se a Política Nacional de Assistência Social (PNAS) criada em 2004, na qual o atendimento à população dar-se-á através da inclusão de usuários nos CRAS e nos Centros de Referência Especializados na Assistência Social (CREAS). Estes proporcionam acolhimento, escuta e fornecem seguimento para a rede de proteção, bem como orientações e encaminhamentos para albergues e emissão de documentos, além de disponibilizar indicadores que monitoram os acessos à rede.

Neste artigo, será discutido o serviço socioassistencial ofertado no CREAS na média complexidade, por tratar-se do respectivo campo de estágio representado pelo Centro Pop de Novo Hamburgo. Este órgão disponibiliza atendimento diário de segunda a sexta, dispõe de café da manhã, fornece higiene pessoal, almoço (somente durante a pandemia de COVID-19), armazenamento de pertences e atendimentos com os técnicos.

Os Serviços de Proteção Social Especial de Média Complexidade compreendem: o Serviço de Proteção e Atendimento Especializado a Famílias e Indivíduos - PAEFI; o Serviço Especializado em Abordagem Social; e o Serviço Especializado para Pessoas em Situação de Rua. Assim, estes serviços têm o objetivo de incluir as pessoas em situação de/na rua no sistema de proteção social e nos serviços públicos, intervindo nas condições de vida dos usuários, preservando a integridade com viés de fortalecimento da autonomia 
desse segmento e a formação de uma identidade coletiva e também individual (FALEIROS, 1999).

A Política Nacional de Assistência Social (BRASIL, 2004) articula-se com o referido estágio a partir do Decreto $\mathrm{n}^{\circ} 7.053$, que instituiu programas de amparo social às pessoas em situação de/na rua na PNAS intitulada como Política Nacional para a População em Situação de Rua (PNPSR), em 2009. Salientam-se em ambas as políticas a busca pela igualdade e equidade no atendimento, por uma vida digna aos usuários, pela valorização do convívio entre estes, entre outros. Percebeu-se, no estágio, a inter-relação entre as duas políticas na tentativa de fortalecer a autonomia, a identidade e a cidadania desse segmento social no acesso aos seus direitos sociais.

De acordo com o Art. $7^{\circ}$ da Política Nacional para a População em Situação de Rua (2009):

I - assegurar o acesso [...] aos serviços e programas que integram as políticas públicas de saúde, educação, previdência, assistência social, moradia, segurança, cultura, esporte, lazer, trabalho e renda; III - instituir a contagem oficial da população em situação de rua; IV - produzir, sistematizar e disseminar dados e indicadores sociais [...]; V - desenvolver ações educativas permanentes que contribuam para a formação [...]; VI - incentivar a pesquisa, produção e divulgação de conhecimentos sobre a população em situação de rua, [...]; VII - implantar centros de defesa dos direitos humanos para a população em situação de rua; VIII - incentivar a criação, divulgação e disponibilização de canais de comunicação para o recebimento de denúncias de violência contra a população em situação de rua, [...]; IX - proporcionar o acesso das pessoas em situação de rua aos benefícios previdenciários e assistenciais e aos programas de transferência de renda, na forma da legislação específica; X - criar meios de articulação entre o Sistema Único de Assistência Social e o Sistema Único de Saúde para qualificar a oferta de serviços; [...] XII - implementar centros de referência especializados para atendimento da população em situação de rua, no âmbito da proteção social especial do Sistema Único de Assistência Social; entre outros (BRASIL, 2009).

No respectivo campo de estágio, através do projeto de intervenção, ocorria o entrelaçamento entre a Política de Assistência Social e da saúde, em virtude do processo saúde-doença dos usuários em atendimento com o Serviço Social do Centro Pop. Isto se viabiliza a partir da referência e contrarreferência nos encaminhamentos para a UBS (Unidade Básica de Saúde), hospitais e o CAPs AD (Centro de Atenção Psicossocial Álcool e Drogas). Estas intervenções serão detalhadas no próximo subitem.

As demandas advindas da população de rua requerem intervenções por parte da equipe vinculada ao Centro Pop, articuladas com a rede intersetorial a fim de fortalecer a cidadania desse segmento, ou seja, compete a esses trabalhadores o enfoque na equidade, no acesso aos direitos sociais, na participação social, na busca ativa pela família de origem, com o intuito de promover qualidade de vida a essa população. Isto exige que o 
Centro Pop disponha de condições de trabalho que possibilitem o acesso aos benefícios eventuais, a inclusão em programas sociais e aos serviços socioassistenciais como novas estratégias de ações vislumbradas, para que a população de/na rua se sinta um cidadão de direito. (BRASIL, 2004; BRASIL, 2009).

Assim, a inter-relação entre a Política Nacional de Assistência Social e a Política Nacional da Pessoa em Situação de Rua representa um avanço quanto ao aparato legal na disputa por recursos orçamentários, recursos de infraestrutura, e recursos humanos, além de prever a participação e o controle social desse segmento, já que trata-se de uma população usuária em maior situação de vulnerabilidade e risco social e, consequentemente, mais suscetível às violações de direitos, constatados através de pesquisas, indicadores e dados sociais.

Deste modo, faz-se necessário que os equipamentos que atendem as pessoas em situação de/na rua ofertem oficinas de geração de trabalho e renda, invistam na escolarização, no acesso à moradia, na prevenção e promoção de saúde, entre outros, a fim de tornar as políticas públicas para esse segmento efetivas, pois conforme Santos e Fachin (2020), atualmente, “O Estado dá tiros no escuro e as políticas públicas acabam sendo um castelo de areia, baseadas numa lógica impositiva em que se pensa em criar uma política para cidadãos em situação de rua sem partir da realidade concreta”.

\section{O PROCESSO DE TRABALHO DE ASSISTENTES SOCIAIS NO CENTRO POP: DESAFIOS E POSSIBILIDADES NA PANDEMIA}

Destaca-se que o trabalho profissional de assistentes sociais requer a apropriação teórica e técnica, com base nas Leis, Portarias e Políticas que respaldam as intervenções da categoria. De acordo com isso, no Centro Pop, era necessária a compreensão da Constituição Federal (BRASIL, 1988), da Lei Orgânica de Assistência Social (BRASIL, 1993), da Política Nacional de Assistência Social (BRASIL, 1993), da Política Nacional para a População em Situação de Rua (BRASIL, 2009), entre outras legislações pertinentes, visto que tais conhecimentos viabilizam a prática profissional com enfoque na luta pela garantia de direitos sociais para a população usuária, além de trazer providências necessárias frente a impossibilidade do acesso de usuários a estas.

No que tange a dimensão teórico-metodológica, isto é, o conjunto de saberes, conhecimentos e referenciais que subsidiam a prática profissional do assistente social, é possível afirmar que esta volta-se, no Centro Pop, para a defesa dos interesses dos usuários que se encontram em situação desigual de poder e de riqueza na sociedade. 
Assim, o trabalho neste campo de estágio exigiu a compreensão da PNAS (BRASIL, 2004) e da PNSPSR (BRASIL, 2009) para fundamentar os posicionamentos e as ações, principalmente no projeto de intervenção, que teve como tema a "Empregabilidade: acesso à renda, estratégia de garantia mínima de subsistência para as pessoas em situação de/na rua em plena pandemia de COVID-19".

Salienta-se que o artigo foi respaldado no materialismo dialético crítico para fundamentar teoricamente o processo de trabalho de assistentes sociais, através de suas categorias: totalidade, historicidade e contradição. Para Lopes (2010), a contradição pode ser reconhecida através das desigualdades e, ao transpormos isto para o campo de estágio, notou-se que essa população está suscetível a ser excluída do sistema de proteção social, uma vez que lhe é exigida documentação civil, acesso aos recursos tecnológicos para cadastramento nos programas de renda mínima e endereço fixo para inserção no mercado de trabalho. Além disso, enfrenta problemas como a baixa escolarização e o processo saúde-doença.

Já no âmbito da historicidade, é possível defini-la como um processo, um movimento, uma dialética, em que se encontra a vida dos sujeitos sociais. Neste sentido, é na história que o ser humano existe e realiza a si mesmo, através de um processo de construção de sua própria trajetória e, ao encontro disso, constatou-se que os usuários do Centro Pop, de modo geral, eram perpassados pela ruptura com suas famílias de origem, pelo abandono afetivo e pela ausência da figura paterna, além de tenderem a reproduzir a história familiar e, por consequência, vivenciar a violação de seus direitos sociais (LOPES, 2010).

Com relação à totalidade, Lopes (2010) a compreende como uma interconexão necessária entre múltiplos fatores a partir de um contexto amplo e singular. Essa categoria é representada na condição dos usuários do Centro Pop com relação a sua identidade versus a rua, como se esta fosse a única dimensão que os representassem como indivíduos. Entretanto, esta perspectiva desconsidera outras situações de riscos, como as necessidades e demandas sociais que exigem intervenções efetivas no fortalecimento da identidade, cidadania e autonomia desses sujeitos. Nesta perspectiva, a prática profissional da assistente social com a população de/na rua no Centro Pop de Novo Hamburgo materializa-se com base no Código de Ética do/a assistente social, no seu conhecimento das legislações, e na defesa dos interesses sociais, conforme refere o Título III, intitulado 
“das Relações profissionais”, em seu Capítulo I, intitulado "Das Relações com os/as Usuários/as", nos artigos $5^{08}$ e $6^{09}$ do referido código (CFESS, 1993).

Já a dimensão ético-política refere-se às atitudes norteadas pelos princípios e valores que devem estar presentes no processo de trabalho do/a assistente social, isto é, compete ao profissional prezar pela defesa de uma nova ordem societária, pela luta pela democracia, socialização da participação política e da riqueza socialmente produzida, assim como pela expansão e consolidação da cidadania (TAVARES, 2020).

As atribuições do/a assistente social no Centro Pop versam sobre o atendimento da população em situação de/na rua, a fim de fortalecer a sua autonomia através da inserção dos usuários no programa Bolsa Família; a confecção de currículo; a emissão de documentos; a localização do paradeiro de familiares; os encaminhamentos para as redes de proteção; entre outros. No entanto, era comum na execução do projeto de intervenção, a interlocução com os demais serviços da política de saúde, embora houvesse certa resistência no acolhimento desses usuários pela sua situação debilitada de saúde, pois alguns faziam uso de substâncias psicoativas, outros tinham doenças degenerativas, ISTs (Infecções Sexualmente Transmissíveis), entre outras.

Durante o estágio também foi possível constatar a falta de monitoramento dos programas, projetos e serviços acessados por esses usuários na vigilância socioassistencial, já que por vezes o atendimento ainda é compensatório, imediatista e pontual. Os serviços de acolhimento institucional têm tempo pré-estabelecido e, muitas vezes, não são conseguidas informações suficientes nos atendimentos para realizar os encaminhamentos necessários, o que fragiliza o vínculo entre os profissionais e os

\footnotetext{
8 Art. $5^{\circ}$ São deveres do/a assistente social nas suas relações com os/as usuários/as: a- contribuir para a viabilização da participação efetiva da população usuária nas decisões institucionais; b- garantir a plena informação e discussão sobre as possibilidades e consequências das situações apresentadas, respeitando democraticamente as decisões dos/as usuários/as, mesmo que sejam contrárias aos valores e às crenças individuais dos/as profissionais, resguardados os princípios deste Código; c- democratizar as informações e o acesso aos programas disponíveis no espaço institucional, como um dos mecanismos indispensáveis à participação dos/as usuários/as; d- devolver as informações colhidas nos estudos e pesquisas aos/às usuários/as, no sentido de que estes possam usá-los para o fortalecimento dos seus interesses; e- informar à população usuária sobre a utilização de materiais de registro audiovisual e pesquisas a elas referentes e a forma de sistematização dos dados obtidos; f- fornecer à população usuária, quando solicitado, informações concernentes ao trabalho desenvolvido pelo Serviço Social e as suas conclusões, resguardado o sigilo profissional; g- contribuir para a criação de mecanismos que venham desburocratizar a relação com os/as usuários/as, no sentido de agilizar e melhorar os serviços prestados; h- esclarecer aos/às usuários/as, ao iniciar o trabalho, sobre os objetivos e a amplitude de sua atuação profissional.

${ }^{9}$ Art. $6^{\circ}$ É vedado ao/à assistente social: a- exercer sua autoridade de maneira a limitar ou cercear o direito do/a usuário/a de participar e decidir livremente sobre seus interesses; b- aproveitar-se de situações decorrentes da relação assistente social-usuário/a, para obter vantagens pessoais ou para terceiros; cbloquear o acesso dos/as usuários/as aos serviços oferecidos pelas instituições, através de atitudes que venham coagir e/ou desrespeitar aqueles que buscam o atendimento de seus direitos.
} 
usuários. De certa maneira, os usuários acabam não tendo suas demandas atendidas na totalidade.

Apesar disso, notou-se que o assistente social busca identificar a demanda dos usuários, a fim de viabilizar a garantia de direitos sociais, o acesso aos serviços oferecidos pela rede de proteção e cidadania de seu espaço atuante (ARGILES; SILVA, 2011). A partir desta intencionalidade, o respectivo projeto de intervenção teve como foco a inclusão desses usuários no mundo do trabalho, na geração de renda, em programas e projetos sociais, entre outros. No respectivo campo de estágio, fomos instigados/as a estabelecer projetos de trabalho que poderiam assegurar o reconhecimento do valor social de seu trabalho, o que serve também como instrumento potente na busca de afirmação do projeto ético político profissional (COUTO, 2009).

A dimensão técnico-operativa ocorreu por meio de entrevistas individuais com sete usuários, também através de encaminhamentos para o registro da documentação pessoal, registros online da carteira de trabalho, articulação com a rede, a exemplo do CAPs AD, UBS, CRAS, entre outros. Segundo Tavares (2020), esta dimensão perpassa a análise da realidade, interpretando-a a partir de aspectos políticos, sociais, éticos, econômicos e culturais.

A entrevista como um instrumento foi utilizado a fim de conhecer a realidade, a particularidade e a história de cada usuário, através de uma visão crítica dialética e da escuta qualificada, deixando o usuário expor suas ideias, sua relação com a rua, e como ele se identificava nesse serviço socioassistencial. Isto favoreceu o vínculo com o usuário, podendo assim intervir na sua realidade social, afinal, essa inter-relação entre usuário e assistente social potencializa a compreensão dos valores, dos sentimentos e das suas concepções acerca do mundo e de sua vida.

Vale ressaltar que, durante a execução do projeto de intervenção, etapa que durou quatro meses, ficou nítido que mesmo após doze anos, a Política Nacional para a População em Situação de Rua, aplicada no município de Novo Hamburgo, ainda é frágil em termos operacionais, principalmente pela falta de recursos da instituição. Ademais, a falta de recursos torna o Centro Pop um serviço com viés imediatista, especialmente em meio à pandemia de Covid-19, em que todas as atividades em grupos, além de oficinas e visitas, foram suspensas, restando apenas abordagens individuais em que os usuários não se sentiram à vontade para exporem suas realidades.

Os desafios para atuar com essa demanda vão muito além dos limites 
institucionais, pois também estão relacionados à discriminação e ao preconceito sofrido na sociedade, inclusive no mundo do trabalho por parte desses usuários. Em uma das intervenções, o usuário expôs que o empregador soube de sua situação de/na rua e o dispensou; assim, o usuário ficou novamente à mercê dos mínimos sociais oferecidos no Centro Pop.

Esta população enfrenta a falta de experiência profissional e de capacitação, dificultando o acesso ao mundo do trabalho, além da falta de albergues com vagas para higienização, descanso e local para lavar suas roupas, fatos que tornam-se obstáculos para a emancipação desses sujeitos. Além disso, alguns dos usuários fazem uso de psicoativos, o que dificulta a manutenção do trabalho, bem como o vínculo familiar e social, favorecendo a permanência na rua e dificultando a superação de sua atual situação tão desigual.

Tanto os usuários quanto os profissionais, por vezes, se frustram, pois os usuários não conseguem superar a situação de vulnerabilidade, a escassez de serviços sociais para uma nova perspectiva de vida, a precarização das políticas públicas e sociais, entre outras. Portanto, torna-se dificultoso mudar a realidade desses usuários, mesmo com a atuação dos profissionais do Centro Pop de Novo Hamburgo na orientação, na divulgação da informação, na sensibilização e na mobilização dos recursos disponíveis no município.

São muitos os desafios a serem superados por parte dos usuários em situação de/na rua e pelas equipes implicadas, porém há de se ter esperança, resiliência, coragem, criatividade e força para a luta pelos direitos sociais dos segmentos tidos como mais vulneráveis e em maior grau de risco social.

\section{CONSIDERAÇÕES}

Por meio do processo interventivo realizado no Centro Pop de Novo Hamburgo/RS, foi possível reconhecer as principais demandas e direitos sociais da população que se encontra em situação de/na rua em meio à pandemia. De modo geral, buscou-se suscitar a discussão com esses usuários sobre o mundo do trabalho, retomada de convívio familiar e comunitário, emissão de documentos pessoais, inserção em programas e projetos sociais objetivando a emancipação, autonomia e superação da situação de/na rua.

Para tanto, é necessário que as políticas sejam revisadas e melhor estruturadas, focando-se na construção de estratégias para que correspondam às principais demandas, 
tais como: a saúde, a educação, a alimentação, a moradia, entre outras. No entanto, este segmento encontra vários impeditivos para adentrar e manter-se no sistema de proteção social.

Destaca-se que mesmo com a criação da Política Nacional para a População em Situação de Rua (BRASIL, 2009), ainda existem muitas barreiras a serem superadas, principalmente com o surgimento da pandemia de Covid-19. Obstáculos como a discriminação, o preconceito, a falta de oportunidade para as pessoas pouco qualificadas, o adoecimento, a intolerância à subjetividade e identidade desse segmento social ainda estão muito presentes nas demandas.

Ressalta-se também a historicidade de vida e a percepção de cada usuário no atendimento do assistente social, ampliando o conhecimento e o entendimento das demandas e necessidades sociais desses indivíduos, pois só assim é possível criar estratégias que correspondam aos interesses desses usuários.

Por fim, evidencia-se a importância dessa vivência para o processo evolutivo tanto pessoal, quanto acadêmico e profissional da autora na implicação pela garantia e defesa dos direitos das pessoas em situação de/na rua, além da necessidade em buscar alternativas por conta do cenário sanitário imposto pela pandemia e de todas as repercussões advindas disso na vida dos usuários e na realidade da instituição.

\section{REFERENCIAS}

ALCHORNE, Sindely. 20 anos de LOAS - análise das normativas nacionais. O Social em Questão, v. 17, n. 30, p. 25-46, 2013. Disponível em: http://osocialemquestao.ser.puc-rio.br/media/OSQ_30_Sindely_2.pdf. Acesso em: 17 out. 2021.

ARGILES, Mariglei dos Santos; SILVA, Vini Rabassa da. Assistência social e população em situação de rua. In: V Jornada Internacional de Políticas Públicas, UFMA, p. 1-11, 2011. Disponível em: http://www.joinpp.ufma.br/jornadas/joinpp2011/CdVjornada/JORNADA_EIXO_2011/I MPASSES_E_DESAFIOS_DAS_POLITICAS_DA_SEGURIDADE_SOCIAL/ASSIS TENCIA_SOCIAL_E_POPULACAO_EM_SITUACAO_DE_RUA.pdf. Acesso em: 15 jun. 2021.

BARDIN, Laurence. Análise de Conteúdo. São Paulo: Martins Fontes, 2016.

BRASIL. Lei Federal no 11.258, de 30 de dezembro de 2005. Brasília: Presidência da República, 2005. Disponível em: http://www.planalto.gov.br/ccivil_03/_ato20042006/2005/lei/111258.htm. Acesso em: 25 out. 2021.

BRASIL. Auxílio Emergencial. Brasília: Caixa Econômica Federal. Disponível em: https://auxilio.caixa.gov.br/\#/inicio. Acesso em: 11 set. 2021. 
BRASIL. Constituição da República Federativa do Brasil. Brasília: Presidência da República, 1988. Disponível em:

http://www.planalto.gov.br/ccivil_03/constituicao/constituicao.htm. Acesso em: 17 out. 2021.

BRASIL. Decreto $\mathbf{n}^{0} \mathbf{7 . 0 5 3}$, de 23 de dezembro de 2009. Brasília: Presidência da República, 2009. Disponível em: http://www.planalto.gov.br/ccivil_03/_ato20072010/2009/decreto/d7053.htm. Acesso em: 26 out. 2021.

BRASIL. Lei n⿳0 8.742 de 07 de dezembro de 1993. Brasília: Presidência da República, 1993. Disponível em: http://www.planalto.gov.br/ccivil_03/leis/18742.htm. Acesso em: 05 out. 2021.

BRASIL. Conferências de Assistência Social. Brasília: Ministério da Cidadania, 2019. Disponível em: https://www.gov.br/cidadania/pt-br/acoes-e-programas/assistenciasocial/participacao-social/conferencias-de-assistencia-social. Acesso em: 26 out. 2021.

BRASIL. Política Nacional de Assistência Social. Brasília: Ministério do Desenvolvimento Social e Combate à Fome, Secretaria Nacional de Assistência Social, 2005. Disponível em:

http://www.mds.gov.br/webarquivos/publicacao/assistencia_social/Normativas/PNAS2 004.pdf. Acesso em: 17 out. 2021.

BRASIL. Orientações Técnicas da Vigilância Socioassistencial. Brasília: Ministério do Desenvolvimento Social, 2013. Disponível em:

https://www.mds.gov.br/webarquivos/publicacao/assistencia_social/Cadernos/Orientaco es_Vigilancia.pdf. Acesso em: 25 out. 2021.

BRASIL. Resolução n ${ }^{0} 109$ de 11 de novembro de 2009. Brasília: Ministério do Desenvolvimento Social e Combate à Fome; Conselho Nacional de Assistência Social, 2009. Disponível em:

https://www.mds.gov.br/webarquivos/public/resolucao_CNAS_N109_\%202009.pdf. Acesso em: 03 nov. 2021.

BRASIL. Resolução no 3.088 de 23 de dezembro de 2011. Brasília: Ministério da Saúde, 2011. Disponível em:

https://bvsms.saude.gov.br/bvs/saudelegis/gm/2011/prt3088_23_12_2011_rep.html. Acesso em: 03 nov. 2021.

BRASIL. Bolsa Família. Brasília: Secretaria Especial do Desenvolvimento Social, 2015. Disponível em: http://mds.gov.br/assuntos/bolsa-familia/o-que-e. Acesso em: 06 set. 2021.

CONSELHO FEDERAL DE SERVIÇO SOCIAL. Código de ética Profissional do Assistente Social. Brasília: CFESS, 1993.

COSTA, Ana Paula. População em situação de rua: contextualização e caracterização. Revista Textos \& Contextos, Porto Alegre, v. 9, n. 4, p. 1-15, dez. 2005. Disponível em: https://revistaseletronicas.pucrs.br/ojs/index.php/fass/article/view/993/773. Acesso em: 11 set. 2021. 
COUTO, Berenice Rojas. Formulação de projeto de trabalho profissional. In:

CONSELHO REGIONAL DE SERVIÇO SOCIAL. Serviço Social: direitos sociais e competências profissionais. Rio Grande do Norte: CRESS/RN, 2009.

CROCHÍK, José. Preconceito: indivíduo e cultura. São Paulo: Casa do Psicólogo, 2006.

LIMA, Telma Cristiane Sasso de; MIOTO, Regina Célia Tamasso; DAL PRÁ, Keli Regina. A documentação no cotidiano da intervenção dos assistentes sociais: algumas considerações acerca do diário de campo. Revista Textos \& Contextos, Porto Alegre, v. 6, n. 1, p. 93-104, jan./jun., 2007. Disponível em:

https://revistaseletronicas.pucrs.br/ojs/index.php/fass/article/view/1048/3234. Acesso em: 20 set. 2021.

DEMO, Pedro. Charme da exclusão social. Campinas: Autores associados, 1998.

FALEIROS, Vicente de Paula. Estratégias em serviço social. São Paulo: Cortez, 1999.

GAMEIRO, Nathália. População em situação de rua aumentou durante a pandemia. Fiocruz, Rio de Janeiro, 8 jun. 2021. Disponível em:

https://www.fiocruzbrasilia.fiocruz.br/populacao-em-situacao-de-rua-aumentoudurante-a-pandemia/. Acesso em: 11 set. 2021.

GIL, Antônio Carlos. Métodos e Técnicas de Pesquisa Social. São Paulo: Atlas, 2008.

GUARESCHI, Pedrinho A. Representações sociais e ideologia. Revista de Ciências Humanas, Florianópolis, v. 1, n. 1, p. 33-46, 2000. Disponível em: https://periodicos.ufsc.br/index.php/revistacfh/article/download/24122/21517/78350. Acesso em: 11 out. 2021.

HERMANSON, Marcos. Trabalho precário, intermitente, é a antessala do desemprego, diz Ricardo Antunes. Brasil de fato, São Paulo, 29 abr. 2019. Disponível em: https://www.brasildefato.com.br/2019/04/29/trabalho-precario-intermitente-e-aantessala-do-desemprego-diz-ricardo-antunes. Acesso em: 05 out. 2021.

IAMAMOTO, Marilda Villela. O Serviço Social na contemporaneidade: trabalho e formação profissional. São Paulo: Cortez, 1999.

IAMAMOTO, Marilda. Villela. A questão Social no capitalismo. Revista Temporalis, Brasília, v. 2, n. 3, jan./jun., 2001. Disponível em:

http://www.abepss.org.br/arquivos/anexos/temporalis_n_3_questao_social201804131245276705850.pdf. Acesso em: 11 set. 2021.

IBGE - INSTITUTO BRASILEIRO DE GEOGRAFIA E ESTATÍSTICA. Desemprego. Rio de Janeiro: IBGE, 2021. Disponível em:

https://www.ibge.gov.br/explica/desemprego.php. Acesso em: 11 set. 2021.

IBGE - INSTITUTO BRASILEIRO DE GEOGRAFIA E ESTATÍSTICA. Panorama. Novo Hamburgo: IBGE, 2020. Disponível em: 
https://cidades.ibge.gov.br/brasil/rs/novo-hamburgo/panorama. Acesso em: 04 set. 2021.

IPEA - INSTITUTO DE PESQUISA ECONÔMICA APLICADA. População em situação de rua cresce e fica mais exposta à Covid-19. Brasília, 12 jun. 2020.

Disponível em:

https://www.ipea.gov.br/portal/index.php?option=com_content $\& v i e w=a r t i c l e \& i d=3581$ 1. Acesso em: 11 set. 2021.

LEWGOY, Alzira Maria Baptista; SILVEIRA, Esalba Maria Carvalho. A entrevista nos processos de trabalho do assistente social. Revista Textos \& Contextos, Porto Alegre, v. 6, n. 2, p. 233-251, jul./dez., 2007. Disponível em:

https://revistaseletronicas.pucrs.br/ojs/index.php/fass/article/view/2315/3245. Acesso em 06 set. 2021.

LOPES, M. S. Introdução ao Serviço Social. Canoas: ULBRA, 2010.

MELLO, Susi. A vida segue nas ruas mesmo em tempos de isolamento. JornalNH, Novo Hamburgo, 26 maio 2020. Disponível em:

< https://www.jornalnh.com.br/noticias/novo_hamburgo/2020/05/26/a-vida-segue-nasruas-mesmo-em-tempos-de-isolamento.html. Acesso em: 11 ago. 2021.

MINAYO, Maria Cecília de Souza. Pesquisa social: teoria, método e criatividade. Petrópolis: Vozes, 2002.

MORADORES de rua: uma situação alarmante. Instituto Humanitas Unisinos, São Leopoldo, 06 maio 2016. Disponível em: http://www.ihu.unisinos.br/185-

noticias/noticias-2016/554631-moradores-de-rua-uma-situacao-alarmante. Acesso em: 06 out. 2021.

NOVO HAMBURGO. Prefeitura inaugura sede própria do Centro Pop. Prefeitura Municipal de Novo Hamburgo: notícias, 09 nov. 2017. Disponível em:

https://www.novohamburgo.rs.gov.br/noticia/prefeitura-inaugura-sede-centro-pop Acesso em: 04 set. 2021.

PEREIRA, Potyara A. P. Necessidades Humanas: subsídios à crítica dos mínimos sociais. São Paulo: Cortez, 2011.

POCHMANN, Marcio. Ajuste econômico e desemprego recente no Brasil metropolitano. Estudos Avançados, São Paulo, v. 29, n. 85, p. 7-19, 2015. Disponível em:

https://www.scielo.br/j/ea/a/hGXbMMGdxsPxjHWCj7LbRTv/?lang=pt\&format=pdf. Acesso em: 11 set. 2021.

POCHMANN, Marcio. Desemprego econômico conjuntural e a situação recente do trabalho no Brasil. Revista NECAT, São Paulo, v. 7, n. 13, p. 11- 27, jan./jun., 2018. Disponível em: http://stat.cbsm.incubadora.ufsc.br/index.php/necat/article/view/5275. Acesso em: 11 set. 2021. 
REINHOLZ, Fabiana. A rua como domicílio: a (des) proteção social à população em situação de rua. Brasil de fato, Porto Alegre, 30 set. 2019. Disponível em:

https://www.brasildefators.com.br/2019/09/30/a-rua-como-domicilio-a-desprotecaosocial-a-populacao-em-situacao-de-rua. Acesso em: 06 out. 2021.

REIS, Carlos Nelson dos. Inclusão social: uma proposta de integração articulada de políticas sociais públicas. Revista Textos \& Contextos, Porto Alegre, v. 4, n. 4, p. 1-26, dez., 2005. Disponível em:

https://www.researchgate.net/publication/277147497_07_Inclusao_social_uma_propost a_de_integracao_articulada_de_politicas_sociais_publicas. Acesso em: 20 set. 2021.

RIO GRANDE DO SUL. Portaria SES n⿳ 750, de 01 de agosto de 2018. Porto Alegre: Secretaria Estadual da Saúde, 2018. Disponível em:

https://saude.rs.gov.br/upload/arquivos/carga20180826/03162637-750.pdf. Acesso em: 12 out. 2021.

SANTOS, João Vitor; FACHIN, Patricia. Políticas públicas para cidadãos em situação de rua são um castelo de areia. Instituto Humanitas Unisinos, São Leopoldo, 07 maio 2020. Disponível em: http://www.ihu.unisinos.br/159-noticias/entrevistas/598680politicas-publicas-para-cidadaos-em-situacao-de-rua-sao-um-castelo-de-areiaentrevista-especial-com-igor-rodrigues. Acesso em: 06 out. 2021.

SPOSATI, Aldaiza; FALCÃO, Maria do Carmo; FLEURY, Sônia Maria Teixeira. Os direitos (dos desassistidos) sociais. São Paulo: Cortez, 2015.

SPOSATI, Aldaíza. Mínimos sociais e seguridade social: uma revolução da consciência da cidadania. Intervenção Social, São Paulo, v. 17, n. 18, p. 197-225, 1998. Disponível em: http://revistas.lis.ulusiada.pt/index.php/is/article/view/967/1087. Acesso em: 26 out. 2021.

TAVARES, Rosilene Aparecida. As dimensões teórico-metodológica, técnico-operativa e ético-política do serviço social no trabalho do assistente social. Revista Serviço Social em Perspectiva, Montes Claros, v. 4, p. 893-906, mar. 2020. Disponível em: https://www.periodicos.unimontes.br/index.php/sesoperspectiva/article/view/1541/1744 . Acesso em: 15 nov. 2021. 